\title{
Change of inspired oxygen concentration in low flow anesthesia
}

\author{
Jiwook Kim, Donghee Kang, Hochul Lee, Sungwon Ryu, \\ Siejeong Ryu, and Doosik Kim
}

Received June 24, 2020

Revised August 25, 2020

Department of Anesthesiology and Pain Medicine, Kosin University Gospel Hospital, Kosin University College of Medicine, Busan, Korea

\author{
Corresponding author \\ Doosik Kim, M.D., Ph.D. \\ Department of Anesthesiology and \\ Pain Medicine, Kosin University \\ Gospel Hospital, Kosin University \\ College of Medicine, 262 Gamcheon- \\ ro, Seo-gu, Busan 49267, Korea \\ Tel: 82-51-990-6283 \\ Fax: 82-51-980-6283 \\ E-mail: kds0728md@gmail.com
}

Background: There are several advantages of low flow anesthesia including safety, economics, and eco-friendliness. However, oxygen concentration of fresh gas flow and inspired gas are large different in low flow anesthesia. This is a hurdle to access to low flow anesthesia. In this study, we aimed to investigate the change in inhaled oxygen concentration in low flow anesthesia using oxygen and medical air.

Methods: A total of 60 patients scheduled for elective surgery with an American Society of Anesthesiologist physical status I or II were enrolled and randomly allocated into two groups. Group H: Fresh gas flow rate (FGF) $4 \mathrm{~L} / \mathrm{min}\left(\mathrm{FiO}_{2} \mathrm{0.5}\right)$. Group L: FGF $1 \mathrm{~L} / \mathrm{min}\left(\mathrm{FiO}_{2} \mathrm{0.5}\right)$. FGF was applied $4 \mathrm{~L} / \mathrm{min}$ in initial phase (10 $\mathrm{min}$ ) after intubation. After initial phase FGF was adjusted according to groups. FGF continued at the end of surgery. Oxygen and inhalation anesthetic gas concentration were recorded for $180 \mathrm{~min}$ at $15 \mathrm{~min}$ interval.

Results: The inspired oxygen concentration decreased by $5.5 \%$ during the first 15 min in the group L. Inspired oxygen decreased by $1.5 \%$ during next $15 \mathrm{~min}$. Inspired oxygen decreased by $1.4 \%$ for 30 to $60 \mathrm{~min}$. The inspired oxygen of group $L$ is $35.4 \pm 4.0 \%$ in 180 min. The group $\mathrm{H}$ had little difference in inspired oxygen concentration over time and decreased by $1.8 \%$ for $180 \mathrm{~min}$.

Conclusions: The inspired oxygen concentration is maintained at 30\% or more for 180 min in patients under $90 \mathrm{~kg}$. Despite some technical difficulties, low flow anesthesia may be considered.

Keywords: Balanced anesthesia; General anesthesia; Inspired oxygen; Low flow.

\section{INTRODUCTION}

Low-flow anesthesia is economical and environmentally-friendly, as it reduces the consumption of $\mathrm{O}_{2}$ and anesthetics during inhalation anesthesia. Clinically, the method is advantageous for raising the temperature and humidity of the inspired gas in patients. Low-flow anesthesia was first introduced by Foldes et al. [1] in 1952, and it was es- tablished when minimum-flow anesthesia $(0.5 \mathrm{~L} / \mathrm{min})$ was introduced by Virtue [2] in 1974. At the same time, the technologically advanced anesthetic machine facilitated safe and accurate rebreathing as well as monitoring, and the currently promoted advantage of the machine is the support for low-flow anesthesia. With the wide use of sevoflurane and desflurane in anesthesia instead of halothane with a high absorption rate, the complicated calculation of

This is an Open Access article distributed under the terms of the Creative Commons Attribution Non-Commercial License (http://creativecommons.org/licenses/by-nc/4.0) which permits unrestricted non-commercial use, distribution, and reproduction in any medium, provided the original work is properly cited.

Copyright (c) the Korean Society of Anesthesiologists, 2020 
the anesthetic gas concentration within the anesthetic circuit during low-flow anesthesia became relatively simple $[3,4]$. Despite the advanced machines and the development and use of anesthetics with low absorption rates, lowflow anesthesia is still a novelty to several anesthesiologists who, due to concerns of safety, tend to resort to the use of fresh gas at a high flow of $\geq 3 \mathrm{~L} / \mathrm{min}$ for anesthesia in clinical practice [5].

In this study, the latest anesthetic device and various monitoring devices were used. The fraction of inspired oxygen $\left(\mathrm{FiO}_{2}\right)$ supplied to the fresh gas was constant, while low-flow anesthesia was applied using $\mathrm{O}_{2}$, medical air, sevoflurane, and desflurane. This study aimed to examine the changes in inspired oxygen concentration within the anesthetic circuit and their stability.

\section{MATERIALS AND METHODS}

\section{Subjects}

This study was conducted after the approval of the Institutional Review Board (no. KUGH-2019-04-14). The goals and methods of the study were explained to the patients and informed consent was obtained from each patient before the study. As a prospective intervention study based on the physical statuses I and II of the American Society of Anesthesiologists, the study recruited 60 patients aged 2065 years scheduled to receive thyroid surgery under general anesthesia. The cases with predicted surgery duration of less than $1 \mathrm{~h}$ were excluded, as the duration is insufficient for monitoring the changes in oxygen saturation. Patients with preoperative pulmonary dysfunction, acute or chronic lung disease, asthma, systemic diseases, such as hypertension and diabetic kidney disease or liver disease, a history of surgery within the previous month, and a history of smoking were excluded. The cases requiring inotropic or antihypertensive injection or blood transfusion were also excluded.

\section{Methods}

The Dräger Primus anesthetic machine (Dräger AG, Germany) and the standard circular respiratory circuit with a heated breathing tube (VentStar Helix heated, Dräger AG) were used. The Vapor ${ }^{\circledR} 2000$ vaporizer (Dräger AG) was used for sevoflurane and D-Vapor ${ }^{\circledR}$ (Dräger AG) was used for desflurane. For each patient, leak tests of the ventilator and respiratory circuit were performed before anesthesia. Drägersorb Free (Dräger AG) was used for the $\mathrm{CO}_{2}$ absorbent, and the substance was replaced with a new one every morning before the daily tasks.

During the surgery, non-invasive techniques were used to assess arterial pressure, electrocardiogram, pulse oxygen saturation, end-tidal $\mathrm{CO}_{2}$ fraction, and body temperature. The standard monitoring procedures, including the Bispectral index score (BIS, Vista ${ }^{\mathrm{TM}}$, USA), were also performed. The measurements were taken from before the induction of anesthesia; arterial pressure was measured at 5 -min intervals, and other recordings were made in real-time.

For the induction of anesthesia, $8 \mathrm{~L} / \mathrm{min}$ of $100 \% \mathrm{O}_{2}$ was used for 2-min spontaneous breathing for denitrification, after which $0.2 \mathrm{mg}$ glycopyrrolate was injected. At the onset of denitrification, remifentanil was initially injected at 0.2 $\mu \mathrm{g} / \mathrm{kg} / \mathrm{min}$. To induce the loss of consciousness, $0.05 \mathrm{mg} /$ $\mathrm{kg}$ midazolam and $1 \mathrm{mg} / \mathrm{kg}$ propofol were injected. As a neuromuscular agent, $0.9 \mathrm{mg} / \mathrm{kg}$ rocuronium was injected, and endotracheal intubation was performed after $90 \mathrm{~s}$. An esophageal thermometer was inserted through the oral cavity.

For the continuation of anesthesia, controlled ventilation was performed while maintaining $6-8 \mathrm{ml} / \mathrm{kg}$ tidal volume, 10-15 times/min respiratory rate, and $30-40 \mathrm{mmHg}$ of end-tidal $\mathrm{CO}_{2}$ fraction. In both groups during the experiment, a minimum alveolar concentration (MAC) of $\geq 0.8$ was maintained, and the bispectral index score was maintained within 40-60. Based on the blood pressure before anesthetic induction, the remifentanil injection was adjusted within a rate of $1-10 \mu \mathrm{g} / \mathrm{min}$. If necessary, $5-10 \mathrm{mg}$ rocuronium was intermittently used for muscular relaxation.

Following intubation, the rate of fresh gas flow was $4 \mathrm{~L} /$ min, whereas the inhaled anesthetics were maintained at $2.2 \mathrm{vol} \%$ sevoflurane and $6.0 \mathrm{vol} \%$ desflurane for $10 \mathrm{~min}$. After $10 \mathrm{~min}$, the fresh gas flow was lowered to $1 \mathrm{~L} / \mathrm{min}$ in the low-flow anesthesia group (group L), for which the sevoflurane and desflurane injections were increased to 2.5 and $7.0 \mathrm{vol} \%$, respectively. In the high-flow anesthesia group (group $\mathrm{H}$ ), the fresh gas flow and anesthetic gas concentration were maintained at identical levels even after 10 min. It was planned that the patients whose inspired oxygen concentration reduced to $\leq 25 \%$ during surgery would be excluded while increasing the fresh gas flow to $4 \mathrm{~L} / \mathrm{min}$. For the cases with $\geq 20 \%$ intraoperative blood pressure in- 
creases or decreases, the plan was to increase or decrease the inhaled anesthetics by $10 \%$. The inspired oxygen, expired oxygen, inspired anesthetic, and expired anesthetic concentrations were recorded at 15-min intervals based on the elapsed time after $10 \mathrm{~min}$ from intubation.

SPSS 20.0 (IBM Co., USA) was used for the statistical analyses. The measured data were expressed as mean \pm SD. The demographic data, such as sex, the types of anesthetic, and the American Society of Anesthesiologists classes were compared using the chi-squared test. The age, height, and weight were compared using the independent $t$-test. The Mann-Whitney $U$ test was used to compare surgery duration and mean arterial pressure. The linear mixed model was used to compare the inspired oxygen concentration, inspired anesthetic concentration, end-tidal $\mathrm{CO}_{2}$, pulse oxygen saturation, and body temperature. $\mathrm{P}<0.05$ represented statistical significance.

\section{RESULTS}

For the analyses, each experimental group contained 30 patients. The demographic statistics for group L and group $\mathrm{H}$ were not significantly different (Table 1). The heart rate, arterial pressure, minute ventilation, and bi-spectral index score of group $\mathrm{L}$ and group $\mathrm{H}$ were not statistically different (Table 2). The end-tidal $\mathrm{CO}_{2}$ was maintained at 32-36
$\mathrm{mmHg}$ in both groups, and the bispectral index score was regulated within 40-60 range.

From the baseline of $10 \mathrm{~min}$ after endotracheal intubation, the inspired oxygen concentrations in group $\mathrm{H}$ and group L were $46.3 \pm 1.0 \%$ and $45.7 \pm 1.6 \%$, respectively; they were not significantly different $(\mathrm{P}=0.107)$. In group $\mathrm{H}$, the difference in the time-dependent inspired oxygen concentration was small, with a $1.8 \%$ reduction within 180 min. In group $\mathrm{L}$, the inspired oxygen concentration during the first 15 min was $40.2 \pm 2.0 \%$, corresponding to a $5.5 \%$ reduction $(\mathrm{P}<0.001)$. After $1 \mathrm{~h}$, the inspired oxygen concentration was $37.3 \pm 2.6 \%$, corresponding to a further decrease by $1.4 \%(\mathrm{P}<0.001)$. The concentration within 120 min after the first 60 min was reduced by only $1.9 \%$, with a recorded value of $35.4 \pm 4.0 \%$. The change in the expired oxygen concentration was similar to that of the inspired oxygen concentration. Between the baseline of $10 \mathrm{~min}$ after intubation and the end-point of anesthesia, the difference between the inspired and expired oxygen concentrations were maintained at approximately $4.8-5.5 \%$ in group $\mathrm{H}$ and 4.9-5.7\% in group L (Fig. 1).

For individual patients, the lowest inspired oxygen concentration during 180 min was $44 \%$ in group $\mathrm{H}$ and $26 \%$ in group L. One of the 30 patients in group L showed a reduction in the inspired oxygen concentration to $<30 \%$, and the lowest inspired oxygen concentration for the remaining

Table 1. Demographic Data

\begin{tabular}{lccc}
\hline \multicolumn{1}{c}{ Variable } & Group $\mathrm{H}(\mathrm{n}=30)$ & Group L $(\mathrm{n}=30)$ & $\mathrm{P}$ value \\
\hline Sex $(\mathrm{M} / \mathrm{F})$ & $9 / 21$ & $10 / 20$ & 0.781 \\
Age $(\mathrm{yr})$ & $47.0 \pm 9.8$ & $49.8 \pm 12.8$ & 0.346 \\
Height $(\mathrm{cm})$ & $163.4 \pm 8.8$ & $163.5 \pm 10.3$ & 0.968 \\
Weight (kg) & $64.8 \pm 14.0$ & $69.7 \pm 12.5$ & 0.158 \\
ASA (I/II) & $13 / 17$ & $12 / 18$ & 0.793 \\
Operative time & $151.5 \pm 37.6$ & $145.5 \pm 32.6$ & 0.534 \\
Inhalation agent (Sevo/Des) & $13 / 17$ & $13 / 17$ & 1.000 \\
\hline
\end{tabular}

Values are presented as number or mean $\pm \mathrm{SD}$. Group $\mathrm{H}$ : fresh gas flow $4 \mathrm{~L} / \mathrm{min}, \mathrm{FiO}_{2} 0.5, \mathrm{O}_{2} 1.5 \mathrm{~L} / \mathrm{min}$, Air $2.5 \mathrm{~L} / \mathrm{min}$; Group L: fresh gas flow $1 \mathrm{~L} / \mathrm{min}, \mathrm{FiO}_{2} \mathrm{0} .5, \mathrm{O}_{2} 0.37 \mathrm{~L} / \mathrm{min}$, Air $0.63 \mathrm{~L} / \mathrm{min}$. ASA: American Society of Anesthesiologist, Sevo: Sevoflurane, Des: Desflurane. P values for differences were determined by using the chi-squares, $t$-test.

Table 2. Hemodynamic Parameters at Baseline

\begin{tabular}{lccc}
\hline \multicolumn{1}{c}{ Variable } & Group $\mathrm{H}(\mathrm{n}=30)$ & Group L $(\mathrm{n}=30)$ & $\mathrm{P}$ value \\
\hline SBP $(\mathrm{mmHg})$ & $114.5 \pm 22.4$ & $110.8 \pm 13.5$ & 0.450 \\
DBP $(\mathrm{mmHg})$ & $73 \pm 14.8$ & $71.2 \pm 9.1$ & 0.503 \\
HR (beats/min) & $85.4 \pm 18.5$ & $87.0 \pm 14.5$ & 0.716 \\
MV (L/min) & $5.8 \pm 1.0$ & $5.6 \pm 1.0$ & 0.387 \\
BIS & $43.8 \pm 8.7$ & $40.3 \pm 6.9$ & 0.187
\end{tabular}

Values are presented as mean $\pm \mathrm{SD}$. Group $\mathrm{H}$ : fresh gas flow $4 \mathrm{~L} / \mathrm{min}, \mathrm{FiO}_{2} 0.5, \mathrm{O}_{2} 1.5 \mathrm{~L} / \mathrm{min}$, Air $2.5 \mathrm{~L} / \mathrm{min}$; Group L: fresh gas flow $1 \mathrm{~L} / \mathrm{min}$, $\mathrm{FiO}_{2}$ 0.5, $\mathrm{O}_{2} 0.37 \mathrm{~L} / \mathrm{min}$, Air $0.63 \mathrm{~L} / \mathrm{min}$. SBP: systolic blood pressure, DBP: diastolic blood pressure, HR: heart rate, MV: minute ventilation, BIS: bispectral index score. $P$ values for differences were determined by using the $t$-test. 

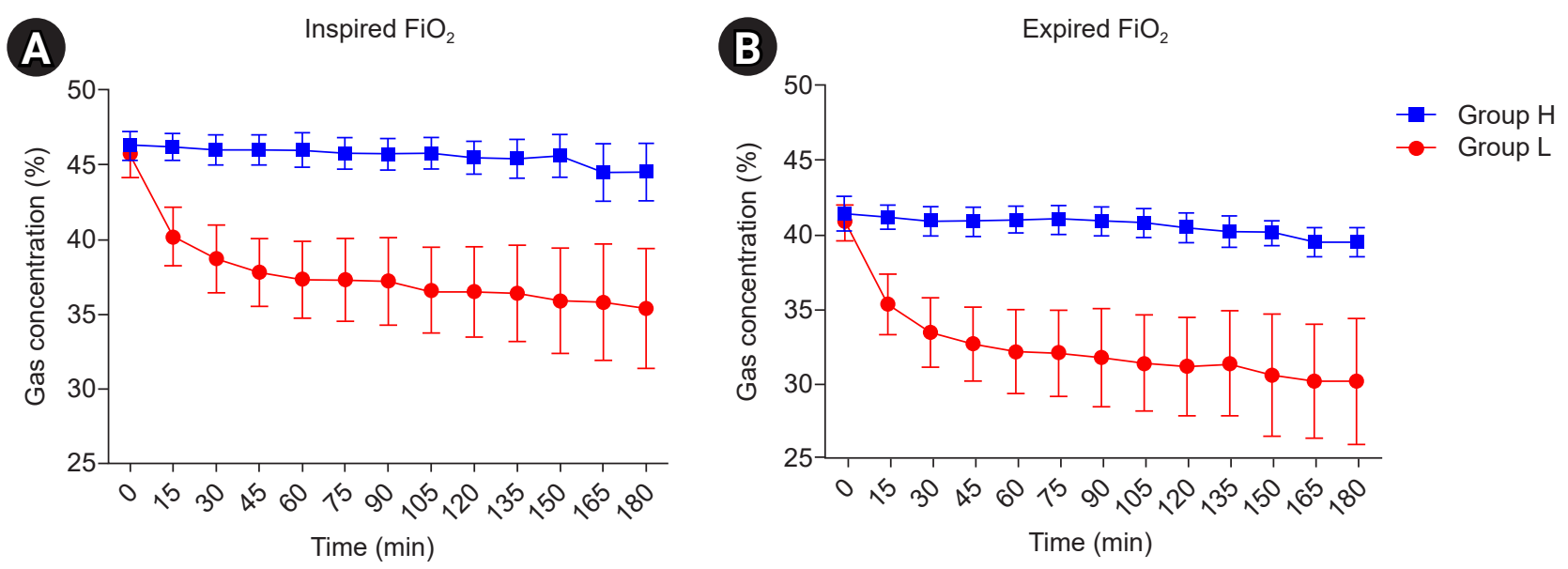

Fig. 1. Changes in inspired (A) and expired (B) oxygen concentration over time in both group. Data represents mean $\pm \mathrm{SD}$. Group $\mathrm{H}=\mathrm{fresh}$ gas flow $4 \mathrm{~L} / \mathrm{min}, \mathrm{FiO}_{2}$ 0.5, $\mathrm{O}_{2} 1.5 \mathrm{~L} / \mathrm{min}$, Air $2.5 \mathrm{~L} / \mathrm{min}$; Group L = fresh gas flow $1 \mathrm{~L} / \mathrm{min}, \mathrm{FiO}_{2} 0.5, \mathrm{O}_{2}$ 0.37 L/min, Air 0.63 L/min.
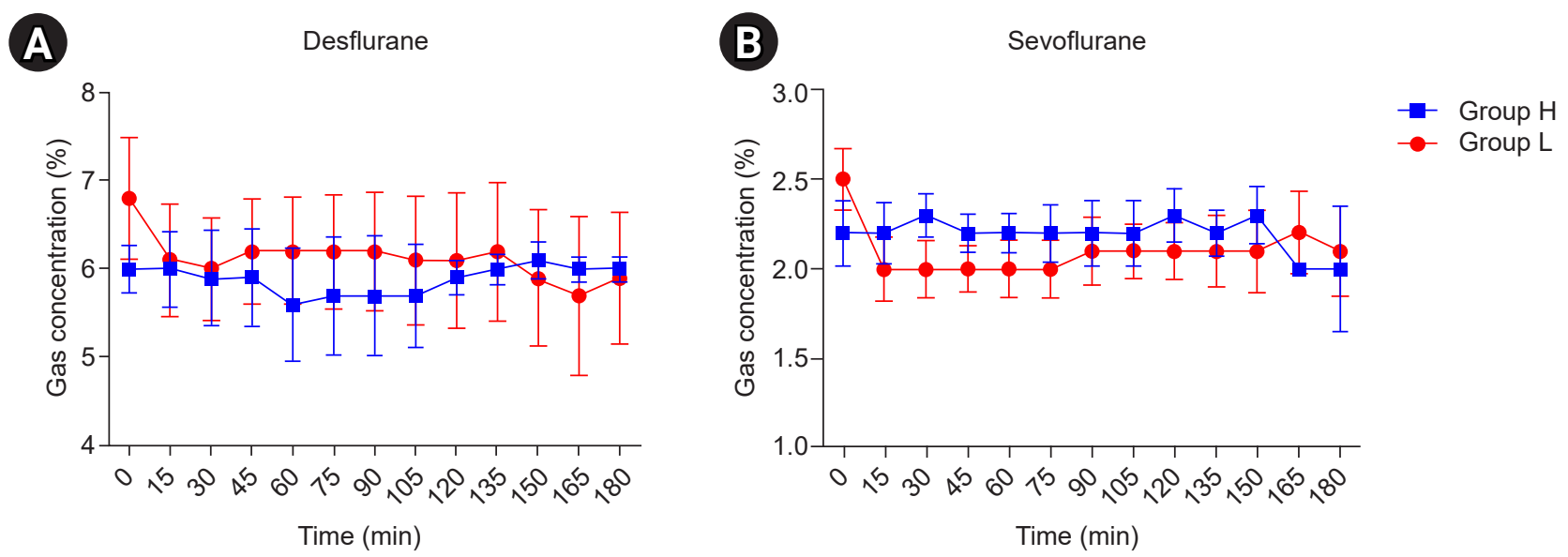

Fig. 2. Changes in inspired desflurane $(A)$ and sevoflurane $(B)$ concentration over time in both group. Data represents mean $\pm S D$. Group $L=$ fresh gas flow $1 \mathrm{~L} / \mathrm{min}, \mathrm{FiO}_{2} 0.5, \mathrm{O}_{2} 0.37 \mathrm{~L} / \mathrm{min}$, Air $0.63 \mathrm{~L} / \mathrm{min}$; Group H = fresh gas flow $4 \mathrm{~L} / \mathrm{min}, \mathrm{FiO}_{2}$ 0.5, $\mathrm{O}_{2} 1.5 \mathrm{~L} / \mathrm{min}, \mathrm{Air} 2.5 \mathrm{~L} / \mathrm{min}$.

29 patients was $32 \%$. In both groups $\mathrm{L}$ and $\mathrm{H}$, there was no drop-out due to a reduction in the inspired oxygen concentration to $<25 \%$.

For the inspired concentration of inhaled anesthetics recorded at the onset of anesthesia, no significant difference was found between group $\mathrm{H}(6.0 \pm 0.3 \mathrm{vol} \%$ desflurane and $2.2 \pm 0.2$ vol\% sevoflurane) and group L ( $6.9 \pm 0.7 \mathrm{vol} \%$ desflurane and $2.5 \pm 0.2$ vol\% sevoflurane $)(\mathrm{P}=0.201)$. The inspired concentrations of inhaled anesthetics after one hour were as follows: $5.7 \pm 0.6 \mathrm{vol} \%$ desflurane and $2.2 \pm$ 0.1 vol\% sevoflurane in group $\mathrm{H} ; 6.3 \pm 0.6 \mathrm{vol} \%$ desflurane and $2.0 \pm 0.2 \mathrm{vol} \%$ sevoflurane in group L (Fig. 2).

For the body temperatures, no significant difference was found between group $\mathrm{H}$ and group $\mathrm{L}(\mathrm{P}=0.248)$, but group L showed slightly higher temperatures with time (Fig. 3 ). The intraoperative temperature was $36.2 \pm 0.3^{\circ} \mathrm{C}$ in group

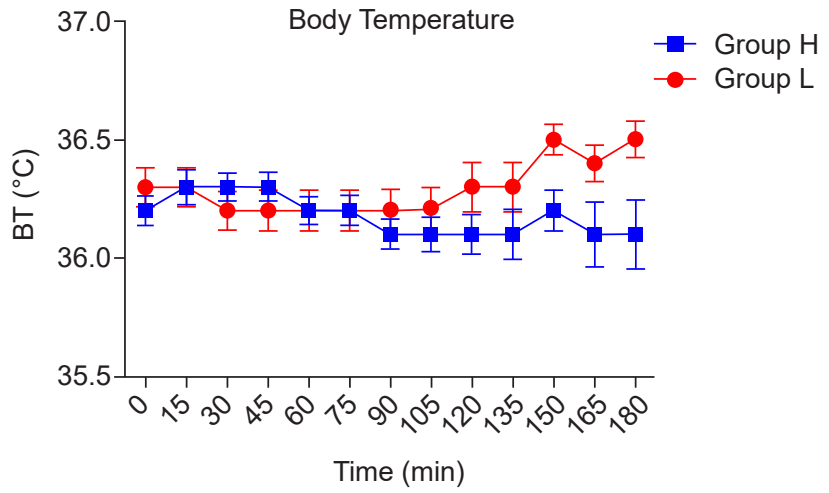

Fig. 3. Changes in esophageal body temperature (BT) over time in both group. Data represents mean $\pm S D$. Group $L=$ fresh gas flow 1 $\mathrm{L} / \mathrm{min}, \mathrm{FiO}_{2} 0.5, \mathrm{O}_{2} 0.37 \mathrm{~L} / \mathrm{min}$, Air $0.63 \mathrm{~L} / \mathrm{min}$; Group $\mathrm{H}=$ fresh gas flow $4 \mathrm{~L} / \mathrm{min}, \mathrm{FiO}_{2} 0.5, \mathrm{O}_{2} 1.5 \mathrm{~L} / \mathrm{min}$, Air $2.5 \mathrm{~L} / \mathrm{min}$.

$\mathrm{H}$ and $36.3 \pm 0.4^{\circ} \mathrm{C}$ in group $\mathrm{L}$ during the early hours and $36.1 \pm 0.3^{\circ} \mathrm{C}$ in group $\mathrm{H}$ and $36.3 \pm 0.5^{\circ} \mathrm{C}$ in group $\mathrm{L}$ after 
$120 \mathrm{~min}$.

In both groups, the pulse oxygen saturation was maintained at $99-100 \%$, with no significant difference $(\mathrm{P}=$ $0.215)$. No case of delayed postoperative recovery, difficulty breathing, or pulmonary complication until discharge was reported.

\section{DISCUSSION}

The benefits of low-flow anesthesia, including the reduced cost based on the reduced use of anesthetic gas, the safety of medical staff working in operation rooms, and environmental protection, are generally accepted [5]. Kim [6] claimed that the continuous monitoring of inspired oxygen concentration and oxygen saturation in low-flow anesthesia enabled the anesthesiologist to focus more on the patient and better understand the pharmacokinetics of the inhaled anesthetics; however, due to the difference between the oxygen concentration in the fresh gas injected to the anesthetic circuit and the inspired oxygen concentration measured by the monitoring device for gas concentration, the anesthesiologists could not readily apply low-flow anesthesia in clinical practice due to safety concerns [7]. The well-known previous studies on low-flow anesthesia mostly focused on the delivery of inhaled anesthetics or used $\mathrm{N}_{2} \mathrm{O}$ and $\mathrm{O}_{2}$. A recent study by Venkatachalapathy et al. [8] also focused on the comparison between the use of medical air and the conventional use of N2O [1,2]. Concerns about the expansion of body cavity or nausea have reduced the use of $\mathrm{N} 2 \mathrm{O}$ while increasing the use of medical air [9]. No study has demonstrated the difference between low-flow anesthesia and the currently popular anesthetic methods using medical air, and this motivated the present study.

Raymond [10] reported that the relationship between $\mathrm{FiO}_{2}$ and inspired oxygen concentration in $1 \mathrm{~L} / \mathrm{min}$ fresh gas flow is linear, and the difference was maintained at approximately $20 \%$. The study also showed that the supply of $\mathrm{O}_{2}$ should be $\geq 0.5 \mathrm{~L} / \mathrm{min}$ to maintain an inspired oxygen concentration of $\geq 30 \%$. Virtue et al. [2] reported that when anesthesia was continued with $0.5 \mathrm{~L} / \mathrm{min}$ fresh gas flow, the inspired oxygen concentration was not reduced to $\leq$ $30 \%$ until 60 min of anesthesia in patients weighing $<80$ $\mathrm{kg}$; in several patients weighing $\geq 80 \mathrm{~kg}$, the inspired oxygen concentration was reduced to $\leq 20 \%$ to increase the proportion of oxygen in fresh gas [11]. Based on the previous studies, the present study determined that $1 \mathrm{~L} / \mathrm{min}$ fresh gas flow was ideal for accessibility and stability in low-flow anesthesia. The study found that the inspired oxygen concentration was not reduced to $\leq 30 \%$ until 60 min of anesthesia in group L, which contained 6 patients weighing $\geq 80 \mathrm{~kg}$. One patient in group L, on the other hand, showed a considerably greater reduction in inspired oxygen concentration in fresh gas flow than was predicted; the patient was $180 \mathrm{~cm}$ in height and $95 \mathrm{~kg}$ in weight, and the inspired oxygen concentration began reducing below $30 \%$ after 60 min of anesthesia, which continued to $26 \%$ until the end of surgery. The simple regression analysis based on bodyweight and inspired oxygen concentration showed that in group L, the inspired oxygen concentration decreased as body weight increased, and the negative correlation was stronger at $120 \min (r=-0.16, \mathrm{R} 2=0.41)$ than at $60 \min (\mathrm{r}=-0.14, \mathrm{R} 2=0.49)$; in group $\mathrm{H}$, the correlation was considerably weak regardless of time $(60 \mathrm{~min}, \mathrm{r}=$ $-0.01, \mathrm{R} 2=0.01 ; 120 \mathrm{~min}, \mathrm{r}=-0.03, \mathrm{R} 2=0.15$ ) (Fig. 4). Considering the report of Okada et al. $[12,13]$ on the relationship between body weight and oxygen consumption during low-flow anesthesia at $0.6 \mathrm{~L} / \mathrm{min}\left(\mathrm{O}_{2}, 0.3 \mathrm{~L} / \mathrm{min}\right.$; $\mathrm{N}_{2} \mathrm{O}, 0.3 \mathrm{~L} / \mathrm{min}$ ) and the correlation between body weight and inspired oxygen concentration found in this study, careful monitoring is required in applying $1 \mathrm{~L} / \mathrm{min}$ fresh gas flow in patients weighing $\geq 90 \mathrm{~kg}$ (Fig. 4).

This study was not designed to analyze the inherent properties of inhaled anesthetics; however, a remark may be made on the related findings. Bailey [14] proposed that to achieve an adequate MAC concentration during lowflow anesthesia, anesthetics should be supplied with sufficient flow for $\geq 10 \mathrm{~min}$ after the onset of anesthesia. Due to the difference between the concentrations of the inhaled anesthetics dial and the anesthesia circuit of the vaporizer, the dial should be adjusted to a level slightly higher than the target during low-flow anesthesia [15]. Based on the findings of Bailey [14] a high flow of $4 \mathrm{~L} / \mathrm{min}$ was applied for $10 \mathrm{~min}$ in the two groups in this study, while the concentration of inhaled anesthetics was slightly increased upon reducing the flow in group L. As the amount of inhaled anesthetics was adjusted based on the BIS and MAC levels in both groups, it is difficult to quantitatively analyze the changes in the concentration of the two inhaled anesthetics. However, it was found that the concentration was maintained at approximately $1 \mathrm{MAC}$ with stability in both groups. Despite the delivery of high-flow inhaled anesthetics for $10 \mathrm{~min}$, a rapid reduction in the concentration of inhaled anesthetics was observed during the first $15 \mathrm{~min}$ in 

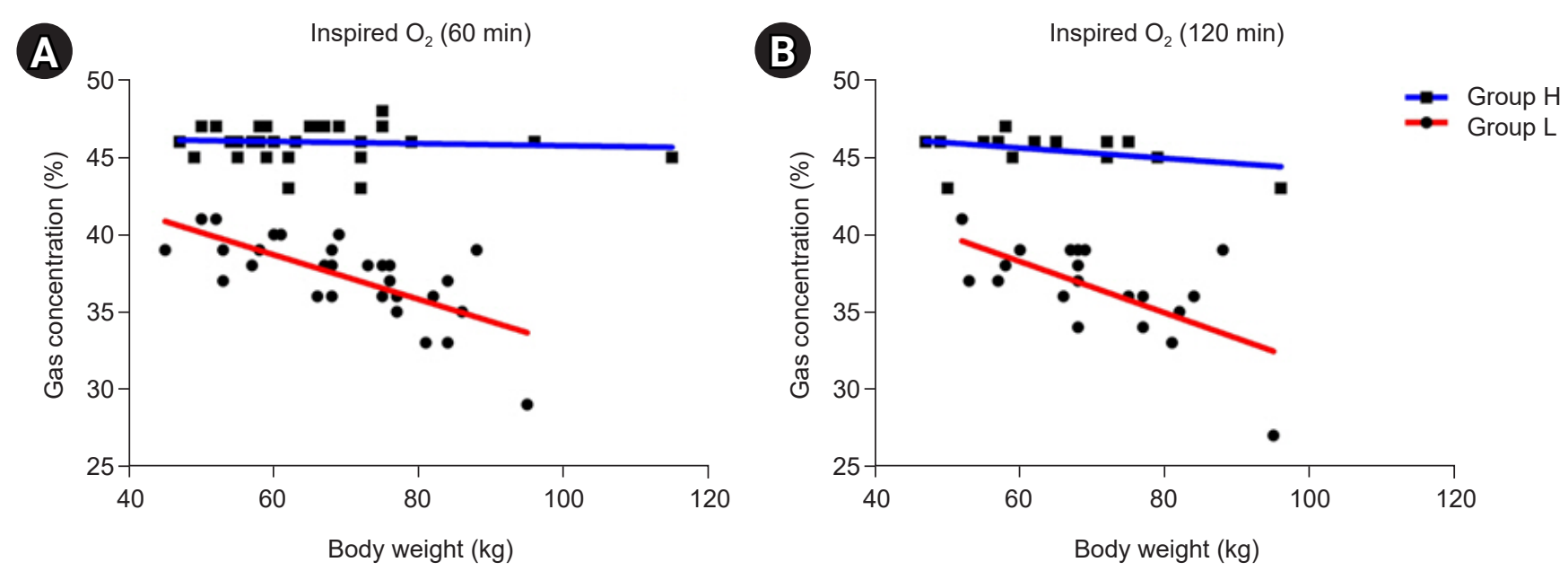

Fig. 4. Correlation between inspired oxygen concentration and body weight in $60 \mathrm{~min}(\mathrm{~A}), 120 \mathrm{~min}(\mathrm{~B})$. Group $\mathrm{H}=$ fresh gas flow $4 \mathrm{~L} / \mathrm{min} \mathrm{FiO} \mathrm{O}_{2} 0.5$, $\mathrm{O}_{2} 1.5 \mathrm{~L} / \mathrm{min}$, Air $2.5 \mathrm{~L} / \mathrm{min}$; Group L = fresh gas flow $1 \mathrm{~L} / \mathrm{min}, \mathrm{FiO}_{2}$ 0.5, $\mathrm{O}_{2} 0.37 \mathrm{~L} / \mathrm{min}$, Air $0.63 \mathrm{~L} / \mathrm{min}$.

group L, followed by relatively steady values. Further studies should obtain the concentration of inhaled anesthetics at 1-min intervals during the first $15 \mathrm{~min}$ of anesthesia, which is predicted to lead to a V-shaped concentration curve for inhaled anesthetics as observed by Bailey [14].

With the advancement and establishment of balanced anesthesia, the continuous injection of narcotic analgesics in addition to inhaled anesthetics and the intermittent or continuous injection of neuromuscular blocking agents have been commonly used, which consequently reduce the proportion of inhaled anesthetics for the maintenance of anesthetic depth [16-18]. During low-flow anesthesia, the relatively slow change in MAC has been pointed out as a significant drawback that inhibits adequate response to surgical stimulation; however, this may complement by the balanced anesthesia method. In this study, narcotic analgesics and neuromuscular blocking agents were used in combination, and the sudden change in the concentration of inhaled anesthetics in group L may not have been necessary.

The body temperatures of groups $\mathrm{L}$ and $\mathrm{H}$ measured in this study were not significantly different, but this may have been due to the use of a heated breathing circuit (VentStar Helix heated, Dräger AG) for maintaining the body temperature. A trend of rise in temperature by approximately $0.2^{\circ} \mathrm{C}$ was observed in group L $120 \mathrm{~min}$ after the onset of anesthesia. This was consistent with the result of Kleemann [19], and as the current emphasis is on maintaining the perioperative body temperature of the patient, the benefits of low-flow anesthesia-related to body temperature maintenance deserves careful attention.
This study has several limitations. First, the study was designed as a pilot study to investigate the relationship between low-flow anesthesia and various patient factors. A simple regression analysis was performed to investigate the correlation between body weight and inspired oxygen saturation, and multiple regression analysis was not performed for height, age, sex, and other variables. Further studies should carry out additional correlation analyses with adequate sample sizes. Second, for the gas analyzer and the vaporizer for sevoflurane and desflurane in the anesthetic machine, deviations may have arisen despite the annual quality control, as a single device was not used for individual measurements. This is expected to be resolved by conducting a prospective randomized controlled study with appropriate sample size.

In conclusion, low-flow anesthesia with $1 \mathrm{~L} / \mathrm{min}$ fresh gas flow was used to maintain the inspired oxygen concentration at $\geq 25 \%$ for up to $3 \mathrm{~h}$. Considering the known advantages related to air pollution and economic issues, lowflow anesthesia should be considered in clinical practice despite one or two technological challenges, compared to the high flow anesthesia with $4 \mathrm{~L} / \mathrm{min}$ fresh gas flow. Further studies should, however, investigate the possibility that $1 \mathrm{~L} / \mathrm{min}$ fresh gas flow may not be sufficient for some patients when the duration of anesthesia exceeds $180 \mathrm{~min}$.

\section{CONFLICTS OF INTEREST}

No potential conflict of interest relevant to this article was reported. 


\section{AUTHOR CONTRIBUTIONS}

Conceptualization: Jiwook Kim, Doosik Kim. Data curation: Hochul Lee, Sungwon Ryu. Formal analysis: Hochul Lee. Methodology: Siejeong Ryu. Project administration: Jiwook Kim. Visualization: Donghee Kang. Writing - original draft: Jiwook Kim. Writing - review \& editing: Jiwook Kim, Siejeong Ryu, Doosik Kim. Supervision: Doosik Kim. Validation: Siejeong Ryu, Doosik Kim.

\section{ORCID}

Jiwook Kim, https://orcid.org/0000-0001-9944-2113

Donghee Kang, https://orcid.org/0000-0001-6614-9244

Hochul Lee, https://orcid.org/0000-0002-9486-3135

Sungwon Ryu, https://orcid.org/0000-0001-6450-197X

Siejeong Ryu, https://orcid.org/0000-0002-0677-4168

Doosik Kim, https://orcid.org/0000-0003-3809-0139

\section{REFERENCES}

1. Foldes FF, Ceravolo AJ, Carpenter SL. The administration of nitrous oxide-oxygen anesthesia in closed systems. Ann Surg 1952; 136: 978-81.

2. Virtue RW. Minimal-flow nitrous oxide anesthesia. Anesthesiology 1974; 40: 196-8.

3. Geoffrey N. Low-flow anaesthesia. Contin Educ Anaesth Crit Care Pain 2008; 8: 1-4.

4. Hargasser S, Hipp R, Breinbauer B, Mielke L, Entholzner E, Rust M. A lower solubility recommends the use of desflurane more than isoflurane, halothane, and enflurane under lowflow conditions. J Clin Anesth 1995; 7: 49-53.

5. Baum J. Low flow anaesthesia: the theory and practice of low flow, minimal flow and closed system anaesthesia. 2nd ed. Boston, Butterworth-Heinemann. 2001. p. 195-234.

6. Kim KO. Low-flow anesthesia in children: theory and clinical practice. Anesth Pain Med 2012; 7: 103-9.

7. Kennedy RR, Hendrickx JF, Feldman JM. There are no dragons: low-flow anaesthesia with sevoflurane is safe. Anaesth Intensive Care 2019; 47: 223-5.

8. Venkatachalapathy R, Cherian A, Panneerselvam S. Changes in gas composition during low flow anaesthesia without nitrous oxide. J Clin Diagn Res 2017; 11: UC29-33.

9. Fernández-Guisasola J, Gómez-Arnau JI, Cabrera Y, del Valle SG. Association between nitrous oxide and the incidence of postoperative nausea and vomiting in adults: a systematic review and meta-analysis. Anaesthesia 2010; 65: 379-87.

10. Raymond JA. Prediction of inspired oxygen concentration within a circle anaesthetic system. Br J Anaesth 1976; 48: 217-23.

11. Togal T, Demirbilek S, Koroglu A, Ersoy O. Minimal and medium flow anaesthesia with isoflurane and desflurane: effects on inspired and expired oxygen and anaesthetic gas concentrations. Internet J Anesthesiol 2008; 18: 1-21.

12. Brody S. Bioenergetics and growth: with special reference to the efficiency complex in domestic animals. New York, Reinhold. 1945. p. xii-1023.

13. Okada K, Asano N, Kimura O, Okada H, Nishio S, Wakusawa R. [Low flow anesthesia using a fresh gas flow of $600 \mathrm{ml} . \mathrm{min}-1$ for 5 hours]. Masui 1997 46: 1321-8. Japanese.

14. Bailey JM. The pharmacokinetics of volatile anesthetic agent elimination: a theoretical study. J Pharmacokinet Biopharm 1989; 17: 109-23.

15. Mapleson WW. The theoretical ideal fresh-gas flow sequence at the start of low-flow anaesthesia. Anaesthesia 1998; 53: 264-72.

16. Crawford ME, Carl P, Andersen RS, Mikkelsen BO. Comparison between midazolam and thiopentone-based balanced anaesthesia for day-case surgery. Br J Anaesth 1984; 56: 165-9.

17. Sneyd JR, Whaley A, Dimpel HL, Andrews CJ. An open, randomized comparison of alfentanil, remifentanil and alfentanil followed by remifentanil in anaesthesia for craniotomy. Br J Anaesth 1998; 81: 361-4

18. Katoh T, Uchiyama T, Ikeda K. Effect of fentanyl on awakening concentration of sevoflurane. Br J Anaesth 1994; 73: 322-5.

19. Kleemann PP. Humidity of anaesthetic gases with respect to low flow anaesthesia. Anaesth Intensive Care 1994; 22: 396 408. 